\title{
Thermal, morphological, and mechanical properties of ethyl vanillin immobilized in polyvinyl alcohol by electrospinning process
}

\author{
Steva Lević • Nina Obradović • Vladimir Pavlović • \\ Bojana Isailović • Ivana Kostić • Miodrag Mitrić • \\ Branko Bugarski $\cdot$ Viktor Nedović
}

Received: 7 October 2013/ Accepted: 30 July 2014/Published online: 29 August 2014

(C) Akadémiai Kiadó, Budapest, Hungary 2014

\begin{abstract}
In this study, polyvinyl alcohol (PVA) nanofibers with ethyl vanillin as an active compound were prepared using electrospinning technique. The final products of electrospinning process were in the form of nanofibers films. PVA/ethyl vanillin nanofibers, having fibers diameters in the range $100-1700 \mathrm{~nm}$, were successfully electrospun from ethanol/water mixture of PVA and ethyl vanillin. The effects of immobilization process on ethyl vanillin thermal properties were investigated by differential scanning calorimetry (DSC). The results of DSC showed significant influence of immobilization process on thermal properties of ethyl vanillin. It was noticed that melting point of immobilized ethyl vanillin was lower $\left(\sim 55^{\circ} \mathrm{C}\right)$ compared to free flavor $\left(\sim 77^{\circ} \mathrm{C}\right)$. Our results showed that films based on PVA/ethyl vanillin nanofibers are mechanically stable.
\end{abstract}

Keywords Polyvinyl alcohol · Ethyl vanillin .

Electrospinning $\cdot$ DSC $\cdot$ Nanofibers

S. Lević · V. Pavlović · V. Nedović

Faculty of Agriculture, University of Belgrade, Nemanjina 6, 11081 Belgrade-Zemun, Serbia

e-mail: vnedovic@agrif.bg.ac.rs

N. Obradović $(\square)$

Institute of Technical Sciences-SASA, Knez Mihajlova 35/IV, 11000 Belgrade, Serbia

e-mail: obradovic.nina@yahoo.com

B. Isailović · I. Kostić · B. Bugarski

Faculty of Technology and Metallurgy, University of Belgrade,

Karnegijeva 4, 11000 Belgrade, Serbia

M. Mitrić

Institute of Nuclear Science Vinča, University of Belgrade,

P.O. Box 522, 11000 Belgrade, Serbia

\section{Introduction}

The productions of polymer films that contain active compounds by electrospinning process have attracted great attention in past decades. Production of films by electrospinning process is based on polymers properties that allow the formation of nano-scale fibers under electrostatic force. The formation of nanofibers is influenced by several parameters: intensity of applied electrical potential, polymer characteristics (i.e., viscosity, conductivity and surface tension), flow rate of polymer solution, and distance between two charged electrodes (i.e., needle and collector). Generally, the electrospinning set-up (Fig. 1) is consisting of dosage system (usually syringe pump with syringe and blunt metal needle), collector and high voltage dc generator.

Electrostatic field causes polymer jet formation at the end of a needle tip, which is attracted by opposite charged collector. Liquid jet formation occurs, when electrostatic force overcomes the surface tension of the polymer solution and polymer solution at the needle tip forms conical shape-Taylor cone. During the jet transition from needle to collector, the fibers are formed simultaneously with a solvent evaporation. As a results, the film consisted of nanofibers is formed on collector's surface [1-3].

Polyvinyl alcohol (PVA) is a non-toxic synthetic polymer that has been used in food industry as moisture barrier, or as an active packaging material. Also, in some products, PVA can be applied as a coating material against negative influence of atmospheric oxygen [4]. PVA is commonly used for production of nanofibers by electrospinning process. These fibers have been designed as carriers for immobilization of various materials like a drugs or food additive [5, 6]. The morphological properties of electrospun PVA nanofibers can be regulated by the addition of 


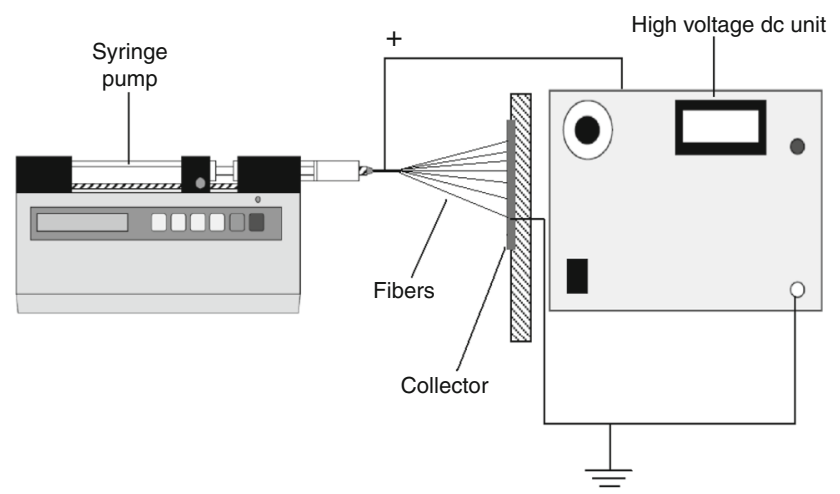

Fig. 1 Schematic of electrospinning process

surfactant in polymer solution prior to electrospinning process [7] or using inorganic materials [8].

Ethyl vanillin (3-ethoxy-4-hydroxybenzaldehyde) has been used as a flavor in food products and cosmetics. This synthetic flavor has more intensive flavoring power compared to vanillin (3-methoxy 4-hydroxybenzaldehyde). On the other hand, vanillin is more soluble in some solvents and solvents mixtures than ethyl vanillin. The solubility of ethyl vanillin in water is lower compared to vanillin, while it is soluble in organic solvents (i.e., ethanol) $[9,10]$. Recently, electrospinning technique has been successfully applied for immobilization of the vanillin in PVA and cyclodextrin. This approach showed significant potential of electrospinning as method for production of immobilized flavor with improved thermal stability and prolonged shelf-life [6].

The goal of this study was to investigate the production of PVA films that contain ethyl vanillin as an active flavor compound. Electrospinning technique was applied for production of nanofibrous films. Since ethyl vanillin is practically insoluble in water, the mixture of ethanol/water was used as a solvent system for dissolving of flavor. The morphology of nanofibers was characterized by scanning electron microscopy (SEM). The effects of the immobilized flavor, as well as ethanol/water solvent system on the morphology of PVA nanofiber were evaluated. The free flavor, PVA film and PVA/ ethyl vanillin nanofibrous films were characterized by Fourier transform infrared spectroscopy (FTIR), X-ray diffraction analysis, differential scanning calorimetry (DSC), and thermogravimetry (TG). In order to evaluate the influences of immobilized flavor on the mechanical properties of electrospun films, the tensile stress of samples was analyzed.

\section{Experimental}

\section{Materials}

PVA (average $M w=70.000-100.000$, hot water-soluble) was purchased from Sigma-Aldrich (USA). Ethyl vanillin was supplied by Hi Media Laboratories Pvt. Ltd. (India). All other chemicals were of analytical reagent grade and used without any further purification.

Preparation of the flavor and polymer solutions

In this study, ethanol-water (volume ratio ethanolwater $=70: 30$ ) mixture was used as a solvent for ethyl vanillin. The working solution $(20 \% \mathrm{~m} / \mathrm{v})$ of ethyl vanillin was prepared by dissolving of flavor in ethanol-water mixture.

PVA $\left(0.15 \mathrm{~g} \mathrm{~mL}^{-1}\right)$ was dissolved in distillated water at $80{ }^{\circ} \mathrm{C}$. Aqueous solution of PVA was mixed with ethanolwater and ethanol-water/ethyl vanillin solution (See Table 1) and stirred on magnetic stirrer for $15 \mathrm{~min}$. The final volume of all mixtures was $3 \mathrm{~mL}$. In addition, $2 \mathrm{~mL}$ of ethanol-water solution was added in order to provide complete flavor dissolution.

\section{Electrospinning procedure}

The syringe $(5 \mathrm{~mL})$ with blunt stainless still needle $(18 \mathrm{G})$ was fixed horizontally on the syringe pump (Pump 11, Harvard Apparatus, US) and the solutions were electrospun by high voltage power supply (Model 30R, Bertan Associates, US). The other process parameters were: flow rate$0.3 \mathrm{~mL} \mathrm{~h}^{-1}$, applied voltage- $13 \mathrm{kV}$, and needle tip to collector distance- $10 \mathrm{~cm}$. A grounded piece of aluminum foil was used for the fiber deposition. The formed films were dried at room temperature for $24 \mathrm{~h}$ to remove the residual solvents mixture if any present.

\section{Measurement and characterization}

The diameters and morphology of the nanofibers were investigated by SEM (JEOL JSM-6390LV). The samples were coated with gold on BALTEC SCD 005 sputter coater prior to SEM analysis. The diameter of fibers was analyzed using ImageJ image analysis program. Around 100 fibers from the SEM images were used for diameter analysis. The thickness of nanofibrous films was measured by a micrometer caliper.

DSC measurements were performed in a DSC-50 (SHIMADZU) DSC thermal analyzer using sample mass of $10.0 \mathrm{mg}$ at heating rates of $10{ }^{\circ} \mathrm{C} \mathrm{min}^{-1}$ under air atmosphere.

Thermogravimetric analysis was carried out by a SETARAM SETSYS Evolution-1750 instrument. The measurements were conducted at a heating rate of $10{ }^{\circ} \mathrm{C} \mathrm{min}{ }^{-1}$ in air atmosphere. FTIR spectrum of free ethyl vanillin, PVA film, and PVA film with flavor was studied using Bomem-Hartmann \& Braun (USA) spectrometer. Spectra were collected using $\mathrm{KBr}$ pellets in the spectral range 4,000-600 $\mathrm{cm}^{-1}$, with the resolution of $4 \mathrm{~cm}^{-1}$. 
Table 1 Compositions of solution used in experiment and fibers/films characteristics

\begin{tabular}{lllll}
\hline Solution composition & $\begin{array}{l}\text { PVA/ethanol- } \\
\text { water/mass ratio }\end{array}$ & $\begin{array}{l}\text { Ethyl vanillin } \\
\text { concentration/\%w/v } \\
\text { in ethanol-water solution }\end{array}$ & Fibers characteristics & Tensile stress/MPa \\
\hline $\begin{array}{l}\text { PVA solution } \\
\text { PVA solution/ethanol-water }\end{array}$ & $100 / 0$ & - & None $^{\mathrm{b}}$ & - \\
PVA solution/ethanol-water/ethyl vanillin & $70 / 30^{\mathrm{a}}$ & - & $\begin{array}{c}\text { Fibers with beads/diameters } \\
\text { in the range } 100-800 \mathrm{~nm}\end{array}$ & $8.4 \pm 2.8$ \\
& $70 / 30^{\mathrm{a}}$ & 20 & $\begin{array}{c}\text { Fibers with beads/diameters } \\
\text { in the range } 100-1700 \mathrm{~nm}\end{array}$ & $23.3 \pm 4.3$ \\
\hline
\end{tabular}

a Additionally add $2 \mathrm{~mL}$ of ethanol-water solution

b Solution was too viscous

The X-ray powder diffraction measurements were performed on a Philips $1050 \mathrm{X}$-ray powder diffractometer using $\mathrm{Ni}$-filtered $\mathrm{Cu}$ Ka radiation and Bragg-Brentano focusing geometry. The patterns were taken in the $5-70^{\circ} 2 \theta$ range with the step of $0.05^{\circ}$ and exposure time of $6 \mathrm{~s}$ per step.

The mechanical properties of the PVA and PVA/ethyl vanillin films were analyzed using an Autograph AG-X Plus High Speed Universal Testing Machine (SHIMADZU). All of the tensile measurements were carried out in triplicate, at room temperature, while the test speed was kept at $1.0 \mathrm{~mm} \mathrm{~min}^{-1}$. The dimensions of the sheet used were $\sim 1 \times 2 \mathrm{~cm} \times \sim 30-60 \mu \mathrm{m}$ (width $\times$ length $\times$ thickness).

\section{Results and discussion}

Effects of ethyl vanillin on morphological properties of nanofibrous films

The obtained PVA films were colorless and transparent, while those with immobilized flavor were nontransparent and white. The thickness of PVA films was found to vary in the range of $\sim 30 \mu \mathrm{m}$ (for PVA films) to $\sim 60 \mu \mathrm{m}$ (for PVA films with immobilized flavor).

Effects of ethyl vanillin addition on fibers formation and fibers diameters

The morphological properties, as well as fibers diameters of the electrospun films were examined using the SEM. The diameter values and images of electrospun PVA and PVA/ethyl vanillin fibers are shown in Fig. 2. The diameters of PVA nanofibers vary from 100 to $800 \mathrm{~nm}$. It can be seen from Fig. 2a, the PVA fibers are irregular and interspersed with beads. These nanofibers properties are in good agreement with results previously reported by Zhang et al. [11] for electrospinning of PVA with the addition of ethanol. According to the same authors, ethanol is not solvent for PVA and causes the reduction of polymer surface tension, as well as viscosity. Hence, as a result of the electrospinning process of PVA/ethanol mixtures, the fibers with beads were formed. On the other hand, the usage of ethanol as a solvent in this study is necessary due to low solubility of ethyl vanillin in water.

The SEM images and diameter distribution histogram for the electrospun PVA film with immobilized ethyl vanillin are shown in Fig. 2b. It can be noticed that for PVA/ethyl vanillin film, fibers diameters are in the range $100-1,700 \mathrm{~nm}$, while the addition of flavor changes not only the morphology of fibers, but also increases the fibers diameters.

\section{Mechanical properties of nanofibrous PVA/ethyl} vanillin films

The effects of immobilized ethyl vanillin on mechanical properties of PVA nanofibrous films are studied and results are shown in Table 1. Our results showed that immobilized flavor affects significantly mechanical properties of PVA nanofibrous film. The tensile stress increased from $8.4 \pm 2.8$ for PVA films to $23.3 \pm 4.3 \mathrm{MPa}$ for PVA/ethyl vanillin films. As we showed above, immobilized ethyl vanillin acts as filler substance and causes increasing of fibers diameters and changed the fiber morphology. As we noticed above, the immobilization of flavor changed the morphology of nanofibers. Hence, variations of mechanical properties of nanofibrous PVA films with immobilized flavor can be expected.

Mollá et al. [12] showed that tensile strength of electrospun Nafion/PVA membranes increased with the increasing of the thickness of these membranes. Our results pointed out that tensile strength of PVA and PVA/ethyl vanillin films depends on polymer concentration, addition of ethanol and ethyl vanilline and modified conditions for fiber formation. 
Fig. 2 Morphology and fibers diameter distribution histograms for the electrospun PVA film without ethyl vanillin $A$ and film with immobilized flavor $B$

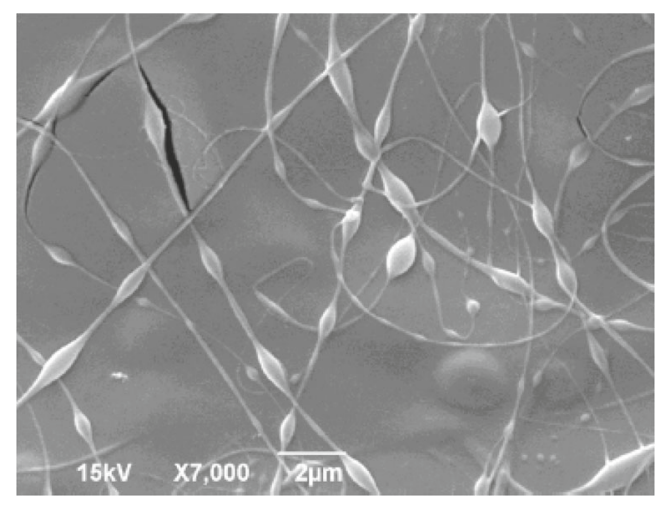

A
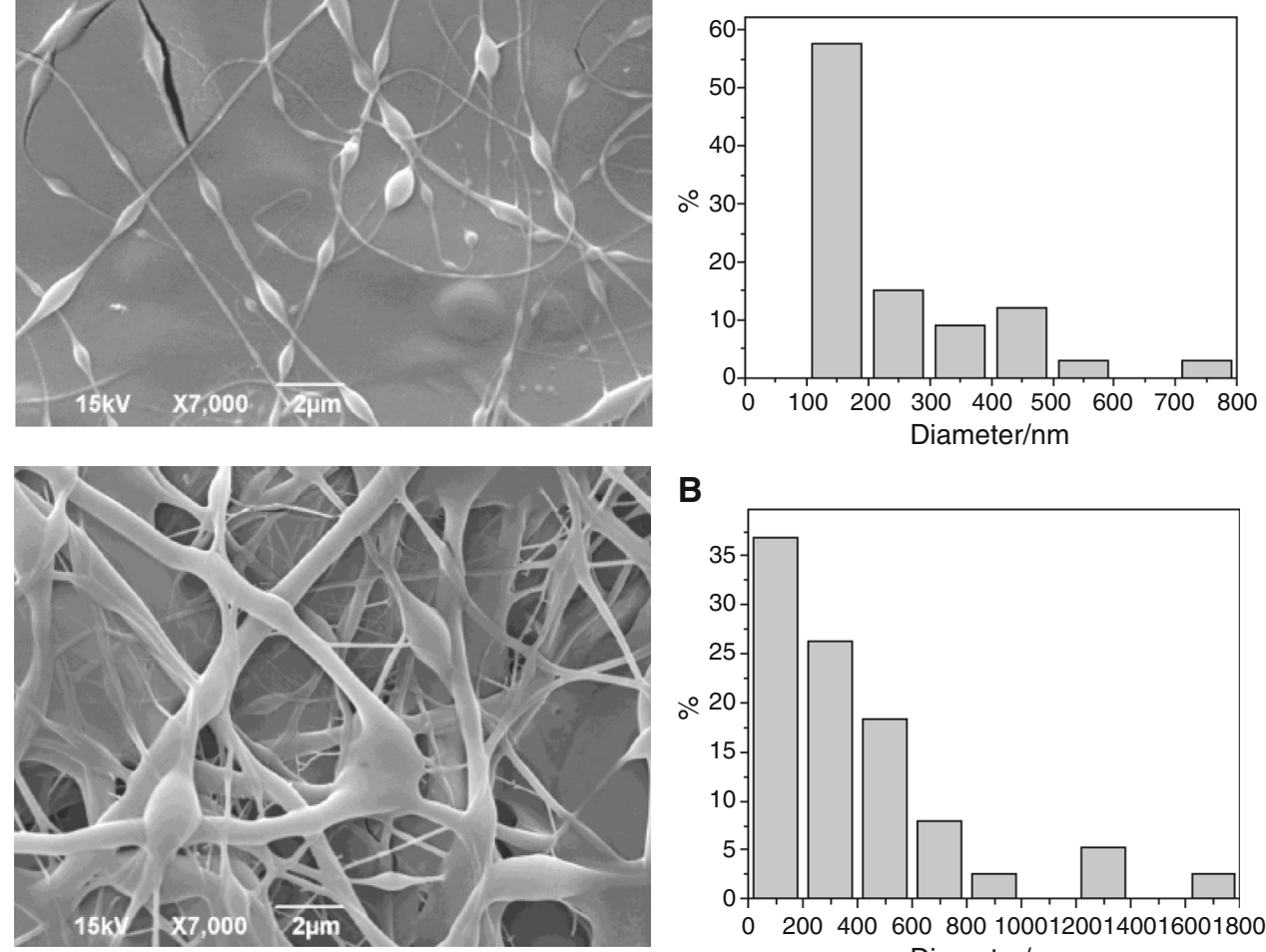

B

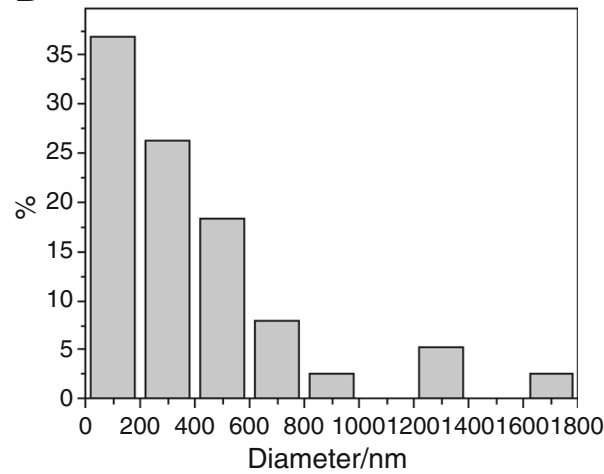

FTIR analysis of nanofibrous PVA/ethyl vanillin films

FTIR analysis was performed in order to examine the functional groups, as well as the existence of PVA and ethyl vanillin in the electrospun nanofibers. As shown in Fig. 3, the FTIR spectrum of free ethyl vanillin displays a number of strong absorption peaks which were previously explained by Levic et al. [13]. The characteristic vibrations detected for PVA nanofibers are: at around $3,423 \mathrm{~cm}^{-1}$ from $\mathrm{OH}$ groups; region $3,000-2,840 \mathrm{~cm}^{-1}$ from $\mathrm{CH}_{2}$ and $\mathrm{C}-\mathrm{H}$; at around $1,640 \mathrm{~cm}^{-1}$ from $\mathrm{OH}$ bending; at around $1,430 \mathrm{~cm}^{-1}$ from $\mathrm{CH}_{2} ; 1,091 \mathrm{~cm}^{-1}$ from $\mathrm{C}-\mathrm{O}$ and at around $850 \mathrm{~cm}^{-1}$ from $\mathrm{C}-\mathrm{C}$ vibrations [14-16].

The FTIR spectrum of PVA/ethyl vanillin film, in the region between 1,750 and $600 \mathrm{~cm}^{-1}$, shows clearly domination of the flavor's bands. On the other hand, in the region 4,000-2,750, the picks corresponding to $\mathrm{OH}$ groups, $\mathrm{CH}_{2}$, and $\mathrm{C}-\mathrm{H}$ in PVA can be clearly distinguished in the film's FTIR spectra.

X-ray powder diffraction analysis of nanofibrous PVA/ ethyl vanillin films

X-ray diffraction patterns of free ethyl vanillin, PVA nanofibrous film, and immobilized flavor are shown in Fig. 4. In the diffractogram of free ethyl vanillin, the characteristic peaks are at diffraction angles $2 \theta$ of $12.2^{\circ}$,

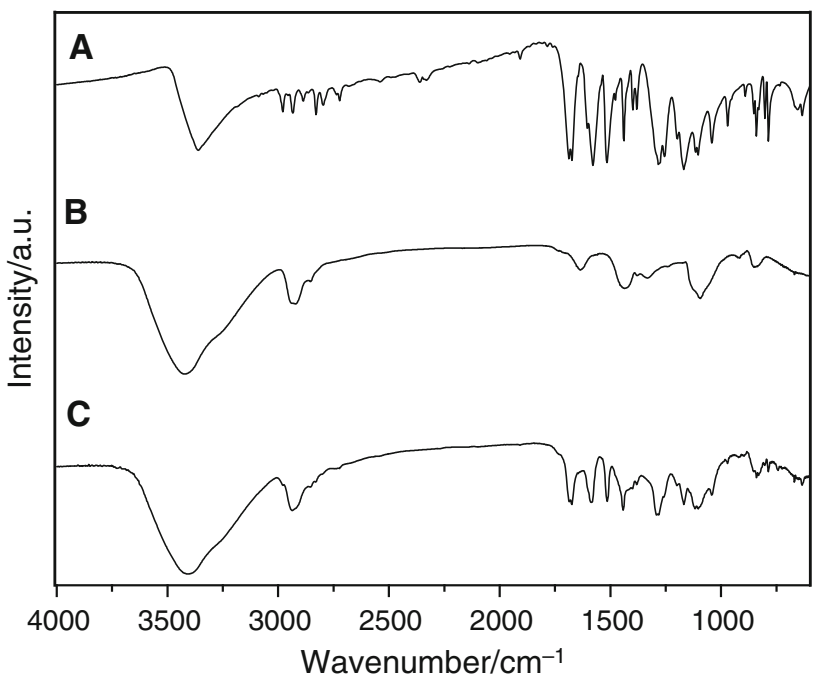

Fig. 3 FTIR spectra of free ethyl vanillin $A$, PVA nanofibrous films $B$ and PVA/ethyl vanillin nanofibrous films $C$

$14.5^{\circ}, 21.1^{\circ}, 22.7^{\circ}, 26.4^{\circ}, 29.2^{\circ}, 37.45^{\circ}$, and $38.85^{\circ}$. The represented X-ray diffraction spectra of free flavor indicate crystalline structure of ethyl vanillin, and it is in accordance with previously published data [17]. The diffractogram of PVA film exhibits broad diffraction pattern at diffraction angles $2 \theta$ of $19.6^{\circ}$ and it is characteristic for semi-crystalline nature of this type of polymer [6]. 


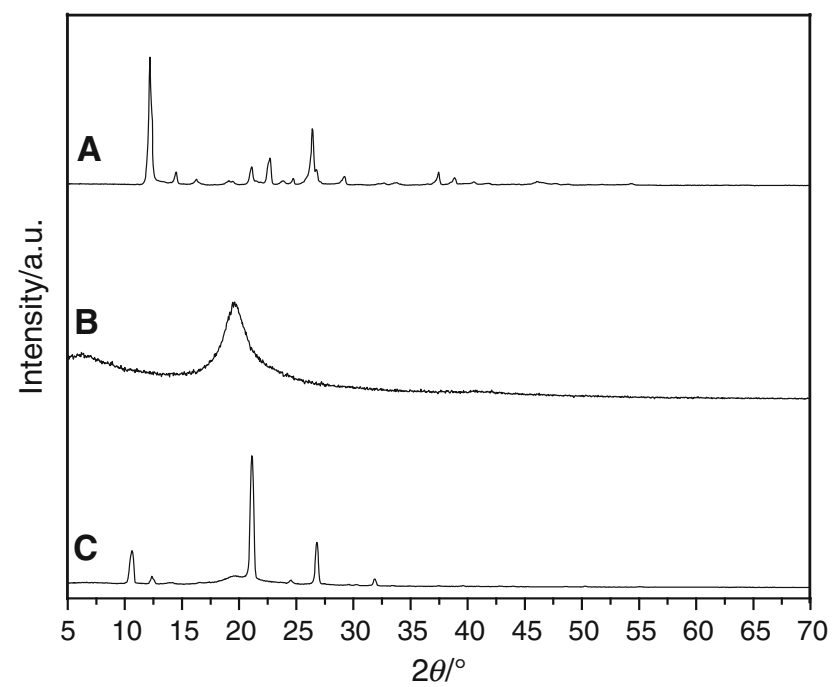

Fig. 4 X-ray diffraction patterns of the free ethyl vanillin $A$, PVA nanofibrous film $B$ and PVA/ethyl vanillin nanofibrous films $C$

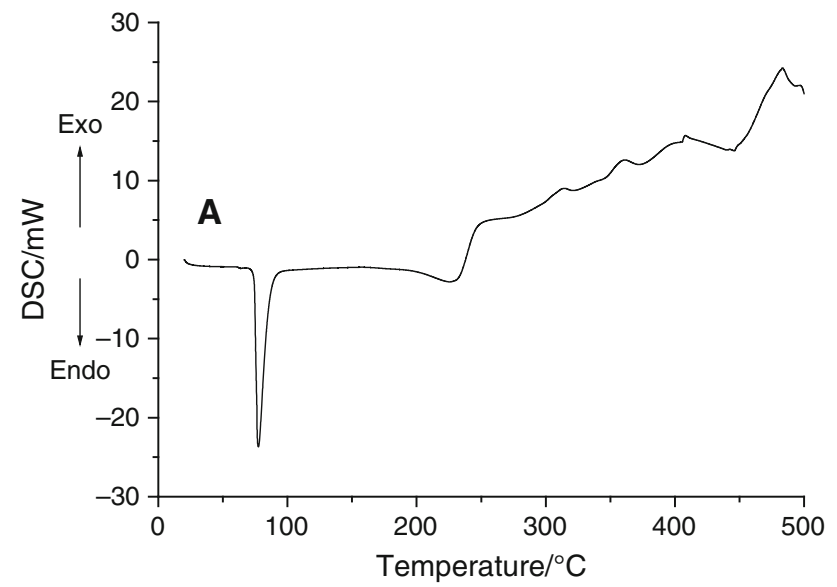

Fig. 5 DSC curve of the free ethyl vanillin $A$

Diffraction pattern of immobilized flavor shows peaks at diffraction angles $2 \theta$ of $10.65^{\circ}, 12.35^{\circ}, 21.1^{\circ}, 24.55^{\circ}$, $26.8^{\circ}$, and $31.9^{\circ}$. The differences in the diffraction pattern of immobilized ethyl vanillin compared to free aroma indicates the modification of the flavor crystal properties which occur as a result of immobilization in PVA matrix. These modifications are most probably the result of the crystals formation, which occur due to change in electrospinning process parameters (e.g., fast solvent evaporation and presence of PVA). Our results point out that immobilized flavor retained crystalline structure after immobilization in PVA matrix. Kayaci and Uyar [6] showed that vanillin immobilized in PVA nanofibers did not show crystalline structure compared to free flavor. Similar results were reported for caffeine and riboflavin

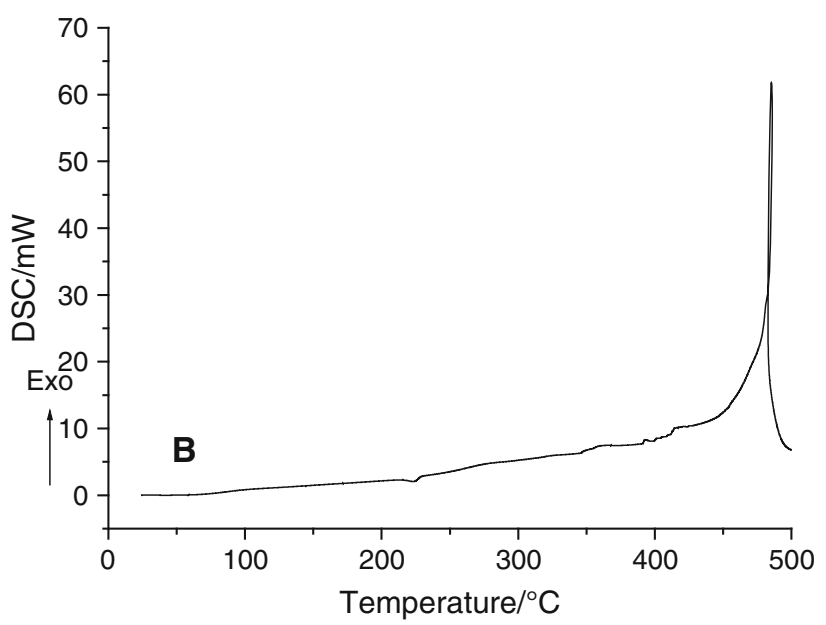

Fig. 6 DSC curve of the PVA nanofibrous films $B$

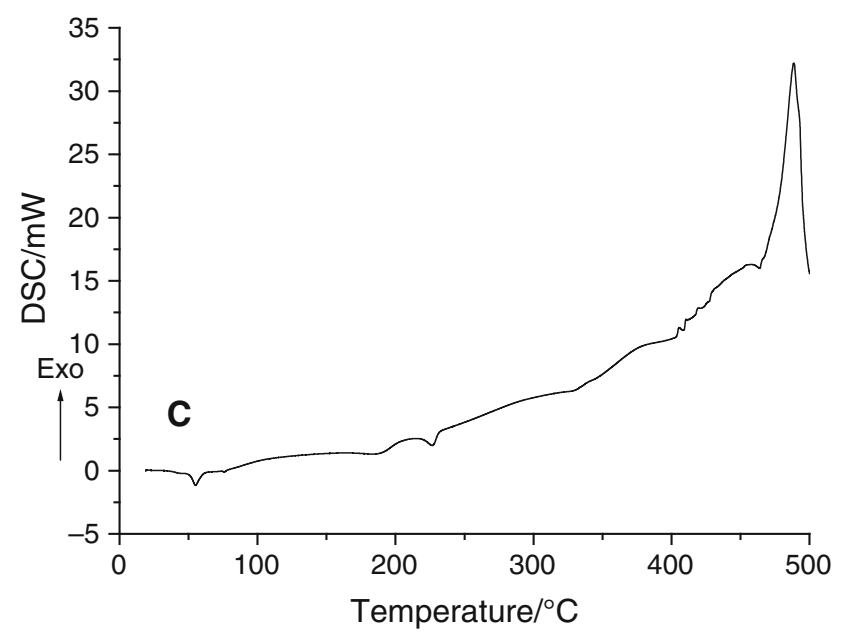

Fig. 7 DSC curve of the PVA/ethyl vanillin nanofibrous films $C$

immobilization into PVA nanofibers by electrospinning process [18]. The differences in our result regarding previous studies could be explained by the fact that ethyl vanillin is low soluble in water, but shows high solubility in ethanol. Ethanol primarily evaporates from water/ethanol mixture during electrospinning process as result of lower boiling point than water. This probably leads to fast flavor crystal growth and formation of crystalline aggregates in the remaining aqueous phase.

DSC analysis of nanofibrous PVA/ethyl vanillin films

Thermal analysis was performed in order to investigate thermal properties of films produced using electrospinning techniques. DSC curves of the free ethyl vanillin, PVA, and 
PVA/ethyl vanillin fibers are shown in Figs. 5-7, and results of thermal analysis are summarized in Table 2. Free ethyl vanillin exhibited a sharp endothermic peak at $77.5^{\circ} \mathrm{C}$ (Fig. 5), which indicates the melting point $\left(T_{\mathrm{m}}\right)$ of flavor [9]. The melting point of immobilized ethyl vanillin (Fig. 7) is shifted to lower temperature $\left(54.9^{\circ} \mathrm{C}\right)$. The values of melting enthalpy $\left(\Delta H_{\mathrm{m}}\right)$ also decreases for immobilized ethyl vanillin compared to free flavor. The decreasing of melting point temperature has been observed for nanofibrous polymer systems [19]. Arinstein et al. [20] showed that depression of melting temperature for polymers occurs by rapidly solvent evaporation during electrospinnig process, which causes the significant influences on polymer chain organization. The depression of melting point for free ethyl vanillin might be explained by changed conditions for flavor crystallization during formation of nanofibers (See above). Also, the presence of PVA affects on thermal properties of ethyl vanillin and indicates that polymer and flavor probably create separated phases in the nanofibers. As we showed above, FTIR analysis did not indicate the presence of strong interactions between this two components.

On the other hand, in the DSC curve of PVA film (Fig. 6), the peak at $227^{\circ} \mathrm{C}$ can be observed, which corresponds with melting of PVA. This peak in the case of PVA/ ethyl vanillin nanofibrous film is at $\sim 226^{\circ} \mathrm{C}$. It seems that addition of ethyl vanillin did not affect significantly on PVA nanofibers melting point. The reason for this might be found in the fact that the free ethyl vanillin does not show peaks (endothermic or exothermic) in around the PVA melting point. Also, based on literature data, the bulk of ethyl vanillin evaporates before the PVA melting point is reached. According to Levic et al. [13], the main mass loss of free ethyl vanillin occurred up to $230^{\circ} \mathrm{C}$, while the encapsulated ethyl vanillin, according to the same authors showed resistance toward mass loss during thermal analysis. Taepaiboon et al. [5] showed that different active compounds may affect on thermal stability of PVA nanofiber by changing kinetics of thermal degradation of polymer. Nevertheless, for application of PVA/flavor nanofibrous film in different areas of food technology and food packaging, it is important to achieve thermal stability of system polymer/flavor in the specific temperature ranges. The applied temperature range in this study corresponds with temperature range applied in food processes [21, 22].

The temperature range from 250 to $500{ }^{\circ} \mathrm{C}$ corresponds to thermal decomposition of PVA and ethyl vanillin. The temperature maximum and corresponding enthalpies are represented as temperature $\left(T_{\mathrm{d}}\right)$ and enthalpy $\left(\Delta H_{\mathrm{d}}\right)$ of decomposition. Karathanos et al. [23] showed that oxidation of vanillin is a process that most likely consists of formation of vanillic acid, while the thermal decomposition occurred at higher temperature (above $300{ }^{\circ} \mathrm{C}$ ). Our result indicates that above $250{ }^{\circ} \mathrm{C}$, the thermal decomposition of free ethyl vanillin is complex process, and probably includes both oxidation and decomposition of flavor. In the temperature range from 250 to $500{ }^{\circ} \mathrm{C}$, the DSC curve of PVA film (Fig. 6) shows exothermic peak at $485.3^{\circ} \mathrm{C}$. According to Modafferi et al. [24], the exothermic reaction in this temperature range is attributed to the decomposition of PVA. The thermal decomposition of PVA is complex process that includes the breakdown of the polymer backbone at high temperatures. On the other hand, the DSC curve of PVA/ethyl vanillin film shows broad peak at $488.8^{\circ} \mathrm{C}$. The exothermic peak for PVA/ethyl vanillin film is occurred at almost the same temperature as in the case of PVA film. The addition of ethyl vanillin causes decreases in enthalpy compared to PVA film. Asran et al. [25] showed that addition of other compound changes the crystal structure of PVA fibers, which is observed by changes in the enthalpies.

Thermogravimetric analysis of nanofibrous PVA/ethyl vanillin films

The results of TG analyses of free ethyl vanillin, PVA nanofibrous film, and PVA/ethyl vanillin nanofibrous film are shown in Fig. 8. Free ethyl vanillin exhibits main mass loss in the temperature region $150-250{ }^{\circ} \mathrm{C}$. The PVA film shows two step mass losses: up to $225^{\circ} \mathrm{C}$ the mass loss is $\sim 10 \%$ and most probably, it is related with water release; the second characteristic mass loss occurs from 225 up to $500{ }^{\circ} \mathrm{C}$, and it is

Table 2 DSC data obtained by analyzing the free ethyl vanillin, PVA nanofibrous films, and PVA/ethyl vanillin nanofibrous films

\begin{tabular}{|c|c|c|c|c|}
\hline \multirow[t]{2}{*}{ Sample } & \multicolumn{2}{|c|}{ Temperature range from RT to $250{ }^{\circ} \mathrm{C}$} & \multicolumn{2}{|c|}{ Temperature range from 250 to $500{ }^{\circ} \mathrm{C}$} \\
\hline & $T_{\mathrm{m}} /{ }^{\circ} \mathrm{C}$ & $\Delta H_{\mathrm{m}} / \mathrm{kJ} \mathrm{g}^{-1}$ & $T_{\mathrm{d}} /{ }^{\circ} \mathrm{C}$ & $\Delta H_{\mathrm{d}} / \mathrm{kJ} \mathrm{g}^{-1}$ \\
\hline Free ethyl vanillin & 77.54 & -10.00 & 483.51 & 0.22 \\
\hline PVA nanofibrous films & - & - & 485.31 & 1.05 \\
\hline \multirow[t]{2}{*}{ PVA/ethyl vanillin nanofibrous films } & $54.95^{\mathrm{a}}$ & -0.0154 & 488.78 & 0.68 \\
\hline & $226.63^{\mathrm{b}}$ & -0.0224 & & \\
\hline
\end{tabular}

\footnotetext{
${ }^{a}$ Indicate first peak on DSC curve

b Indicate second peak on DSC curve
} 


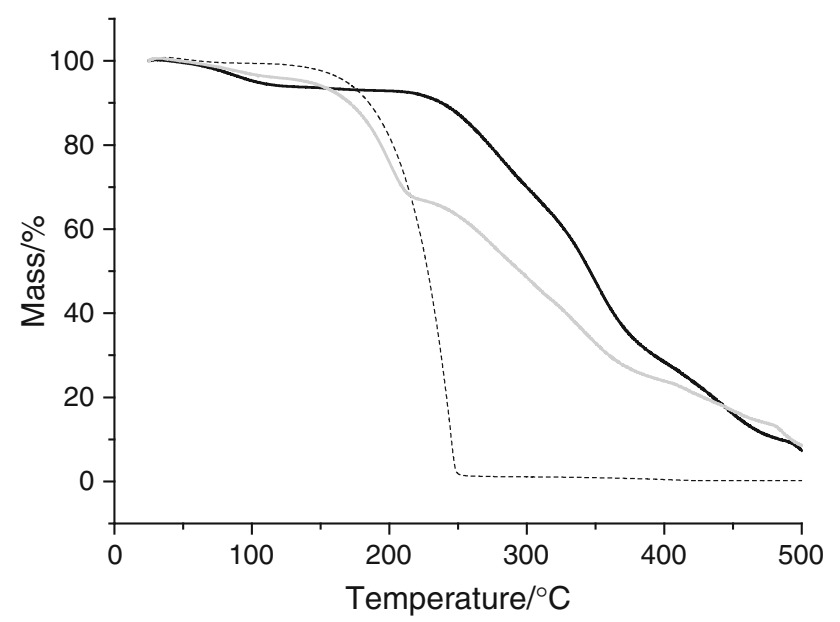

Fig. 8 TG curves of the free ethyl vanillin (dashed line), PVA nanofibrous film (dark line), and PVA/ethyl vanillin nanofibrous films (gray line)

associated with polymer decompositions. The PVA/ethyl vanillin TG curve exhibits more complex mass loss kinetics regarding free flavor or PVA film. The mass loss of immobilized flavor could be separated in three regions: (i) water loss from PVA film, (ii) flavor release, and (iii) finally polymer and flavor thermal decomposition. Water release occurs in the same temperature region in which ethyl vanillin starts to evaporate, so it is relatively complex to distinguish these two processes. Nevertheless, the influence of electrospinning process on ethyl vanillin thermal properties is pronounced. Up to $250{ }^{\circ} \mathrm{C}$, the immobilized flavor shows $\sim 37 \%$ mass loss, compared to free flavor (i.e., $98 \%$ mass loss) or PVA film (i.e., $\sim 10 \%$ mass loss).

Our results point out that electrospinning of ethyl vanillin in the form of nanofibrous film is based on PVA as matrix material modifies flavor thermal properties and releases kinetics at elevated temperature. The results of thermal analyses of immobilized flavor could be useful for further application of electrospinning process for food additives protection.

\section{Conclusions}

We showed that electrospinning technique is suitable for production of nanofibrous PVA films that contain active food ingredient. Electrospun PVA nanofibrous films with immobilized ethyl vanillin have been successfully prepared by ethanol/water mixture as a solvent. The morphology and diameters of fibers were strongly influenced by the immobilized flavor. The results of mechanical tests and FTIR analysis showed that films with immobilized ethyl vanillin were mechanically stable with clearly observed the presence of PVA and immobilized flavor in FTIR spectrum of electrospun films. DSC analysis showed that in the range from room temperature up to $250^{\circ} \mathrm{C}$, the endothermic peaks occurred. These peaks were identified as melting points of free and immobilized ethyl vanillin and PVA. The results of this study showed that electrospinning process affected ethyl vanillin thermal properties by decreasing its melting point compared to pure flavor. In the temperature range from 250 up to $500{ }^{\circ} \mathrm{C}$, the dominant process was thermal decomposition of PVA and ethyl vanillin.

Acknowledgements This work was supported by the Ministry of Education, Science and Technological Development, Republic of Serbia (Project Nos. III46001, III46010 and OI172057).

\section{References}

1. Reneker HD, Chun I. Nanometre diameter fibres of polymer, produced by electrospinning. Nanotechnology. 1996;7:216-23.

2. Ramakrishna S, Fujihara K, Teo EW, Lim CT, Ma Z. An introduction to electrospinning and nanofibers. Singapore: World Scientific Publishing; 2005.

3. Qin X, Wu D. Effect of different solvents on poly (caprolactone)(PCL) electrospun nonwoven membranes. J Therm Anal Calorim. 2012;107:1007-13.

4. Goodship V, Jacobs D. Polyvinyl alcohol: materials, processing and applications. In: Gardiner F, editor. Rapra Review Reports 16, Report 192. Shrewsbury, Shropshire: Smithers Rapra Technology; 2005. pp. 4-16.

5. Taepaiboon P, Rungsardthong U, Supaphol P. Drug-loaded electrospun mats of poly (vinyl alcohol) fibres and their release characteristics of four model drugs. Nanotechnology. 2006;17: 2317-29.

6. Kayaci F, Uyar T. Encapsulation of vanillin/cyclodextrin inclusion complex in electrospun polyvinyl alcohol (PVA) nanowebs: prolonged shelf-life and high temperature stability of vanillin. Food Chem. 2012;133:641-9.

7. Jia L, Qin XH. The effect of different surfactants on the electrospinning poly (vinyl alcohol)(PVA) nanofibers. J Therm Anal Calorim. 2013;112:595-605.

8. Ma Q, Mao B, Cebe P. Inorganic reinforcement in PET/silica electrospun nanofibers. J Therm Anal Calorim. 2012;109:1245-51.

9. Burdock AG. Fenaroli's handbook of flavor ingredients. 6th ed. Boca Raton: CRC Press; 2009.

10. Hussain K, Thorsen G, Malthe-Sørenssen D. Nucleation and metastability in crystallization of vanillin and ethyl vanillin. Chem Eng Sci. 2001;56:2295-304.

11. Zhang C, Yuan X, Wu L, Han Y, Sheng J. Study on morphology of electrospun poly (vinyl alcohol) mats. Eur Polym J. 2005;41:423-32.

12. Mollá S, Compañ V, Gimenez E, Blazquez A, Urdanpilleta I. Novel ultrathin composite membranes of Nafion/PVA for PEMFCs. Int J Hydrog Energy. 2011;36:9886-95.

13. Levic S, Djordjevic V, Rajic N, Milivojevic M, Bugarski B, Nedovic V. Entrapment of ethyl vanillin in calcium alginate and calcium alginate/poly (vinyl alcohol) beads. Chem Pap. 2013;67:221-8.

14. Li L, Hsieh YL. Chitosan bicomponent nanofibers and nanoporous fibers. Carbohydr Res. 2006;341:374-81.

15. Arias M, Pantojas MV, Perales O, Otaño W. Synthesis and characterization of magnetic diphase $\mathrm{ZnFe}_{2} \mathrm{O}_{4} / \gamma-\mathrm{Fe}_{2} \mathrm{O}_{3}$ electrospun fibers. J Magn Magn Mater. 2011;323:2109-14. 
16. Mansur SH, Sadahira MC, Souza NA, Mansur APA. FTIR spectroscopy characterization of poly (vinyl alcohol) hydrogel with different hydrolysis degree and chemically crosslinked with glutaraldehyde. Mater Sci Eng C. 2008;28:539-48.

17. Li Y, Zhang $X$, Zhenga J. Wang X. 3-Ethoxy-4-hydroxybenzaldehyde. Acta Crystallogr E. 2008:E64.

18. Li X, Kanjwal MA, Lin L, Chronakis SI. Electrospun polyvinylalcohol nanofibers as oral fast-dissolving delivery system of caffeine and riboflavin. Colloid Surf B. 2013;103:182-8.

19. Han J, Branford-White JC, Zhu ML. Preparation of poly(E-caprolactone)/poly(trimethylene carbonate) blend nanofibers by electrospinning. Carbohydr Polym. 2010;79:214-8.

20. Arinstein A, Liu Y, Rafailovich M, Zussman E. Shifting of the melting point for semi-crystalline polymer nanofibers. Europhys Lett. 2011;93:46001.

21. de Roos KB. Effect of texture and microstructure on flavour retention and release. Int Dairy J. 2003;13:593-605.
22. de Roos KB. Understanding and controlling the behaviour of aroma compounds in thermally processed foods. Trends Food Sci Technol. 2006;17:236-43.

23. Karathanos TV, Mourtzinos I, Yannakopoulou K, Andrikopoulos $\mathrm{KN}$. Study of the solubility, antioxidant activity and structure of inclusion complex of vanillin with b-cyclodextrin. Food Chem. 2007;101:652-8.

24. Modafferi V, Panzera G, Donato A, Antonucci PL, Cannilla C, Donato N, Spadaro D, Neri G. Highly sensitive ammonia resistive sensor based on electrospun $\mathrm{V}_{2} \mathrm{O}_{5}$ fibers. Sens Actuator $\mathrm{B}$. 2012;163:61-8.

25. Asran SA, Henning S, Michler HG. Polyvinyl alcohol-collagenhydroxyapatite biocomposite nanofibrous scaffold: mimicking the key features of natural bone at the nanoscale level. Polymer. 2010;51:868-76. 